\title{
BMJ Open Impact of COVID-19 pandemic on haemorrhagic stroke admissions: a systematic review and meta-analysis
}

\author{
Yijie You (D) , ${ }^{1}$ Yunlian Niu, ${ }^{2}$ Fengbing Sun, ${ }^{1}$ Jian Zhang, ${ }^{1}$ Sheng Huang, \\ Peiyuan Ding, ${ }^{1}$ Xuhui Wang ${ }^{3}$
}

To cite: You Y, Niu Y, Sun F, et al. Impact of COVID-19 pandemic on haemorrhagic stroke admissions: a systematic review and meta-analysis. BMJ Open 2021;11:e050559. doi:10.1136/ bmjopen-2021-050559

- Prepublication history and additional supplemental material for this paper are available online. To view these files, please visit the journal online (http://dx.doi.org/10.1136/ bmjopen-2021-050559)

Received 23 February 2021 Accepted 19 November 2021

Check for updates

(c) Author(s) (or their employer(s)) 2021. Re-use permitted under CC BY-NC. No commercial re-use. See rights and permissions. Published by BMJ.

${ }^{1}$ Department of Neurosurgery, Shanghai Jiaotong University School of Medicine, Xinhua Hospital Chongming Branch, Shanghai, China

${ }^{2}$ Department of Neurology, Shanghai Jiaotong University School of Medicine, Xinhua Hospital Chongming Branch, Shanghai, China

${ }^{3}$ Department of Neurosurgery, Xinhua Hospital Affiliated to

Shanghai Jiaotong University School of Medicine, Shanghai, China

\section{Correspondence to}

Dr Yijie You;

cematianya@foxmail.com and

Mr Peiyuan Ding;

13564338032@163.com

\section{ABSTRACT}

Background and purpose COVID-19 pandemic, a global health crisis, is disrupting the present medical environment. This systematic review and meta-analysis aimed to evaluate the impact of the COVID-19 pandemic on stroke hospitalisations, especially haemorrhagic stroke. Methods The EMBASE, PubMed, Web of Science, Elsevier, Medline, Cochrane Library and Google Scholar electronic databases were searched for all relevant studies. Two researchers independently screened the studies, extracted data and assessed the quality of the included studies. Odds ratio (OR), total events, $\mathrm{OR}$ and $95 \% \mathrm{Cl}$ were considered as the effect size. A fixed-effects model was used to pool the study-specific estimate. The present study was performed by using Review Manager (V.5.3.0) software. We assessed the risk of bias using the Newcastle-0ttawa Scale.

Results A total of 17 studies with 14445 cases were included. Overall, the number of stroke admissions is lower in the pandemic period versus the control period (6252 vs 8193). The difference of haemorrhagic stroke is significant, with 1233 of 6252 cases in the pandemic group and 1621 of 8193 cases in the control group. Intracerebral haemorrhage is present in 461 of 1948 cases in the pandemic group and 618 of 2734 cases in the control group. As for subarachnoid haemorrhage, the difference between the two groups is significant, with 70 of 985 cases in the pandemic group and 202 of 1493 cases in the control group.

Conclusions The number of stroke admissions is lower in the pandemic period compared with the control period. There is a higher rate of haemorrhagic stroke in the pandemic period. Subgroup analysis identifies a significant increase in the occurrence of intracerebral haemorrhage in the pandemic period. Due to limited data and the impact of a single article, the impact of COVID-19 pandemic on subarachnoid haemorrhage is unclear.

\section{INTRODUCTION}

In December 2019, COVID-19 or SARS-CoV-2 was first reported in Wuhan, China. ${ }^{1}$ On 30 January 2020, the WHO declared COVID-19 as a Public Health Emergency of International Concern. $^{2}$ As of 16 August 2021, there have been over 206.69 million confirmed cases and 4352488 deaths globally, resulting in serious social and economic implications. ${ }^{34}$

\section{Strengths and limitations of this study}

Because we collected results from different regions the meaning of our study is wide and important.

- The result of this study is credible by meta-analysis, which could further explain disputes between different articles.

- This study lacks information about stroke severity and prognoses, which might have to some extent underestimated impacts of the pandemic on stroke.

- The total number of inpatients in the pandemic was not reported, so the prevalence of stroke is inconclusive.

- Although our meta-analysis indicates higher morbidity of intracerebral haemorrhage, the reliability needs to be verified by further researches because of the small sample size.

Stroke is the second leading cause of death and functional inability worldwide, and one of the main contributors of disability-adjusted life years among neurological disorders. ${ }^{56}$ The burden of stroke is projected to increase via absolute numbers of incident strokes and deaths. ${ }^{7}$ The main contributor to stroke burden is ischaemic stroke, followed by intracerebral haemorrhage (ICH) and subarachnoid haemorrhage (SAH). ${ }^{78}$ To prevent and treat stroke, most countries try to establish major and emerging strategies, including activities that reinforce the local healthcare system through the establishment of a social, economic, environmental and cultural combination. ${ }^{9} 10$

Unfortunately, the COVID-19 outbreak affected acute stroke services, both direct and indirect. During the pandemic, a lot of people refuse to visit the hospital due to nosocomial infection, and some studies indicate that the incidence of acute conditions such as myocardial infarction and ischaemic stroke has reduced. ${ }^{11} 12$ The World Stroke Organizatiton (WSO) survey showed that the number of acute stroke admissions was reduced in multiple 
countries, including Chile, Colombia, Iran, Greece, the UK, Belgium and Italy. ${ }^{13}$ In addition, concerns have been raised about the impact of COVID-19 pandemic on haemorrhagic stroke (HS), including ICH and SAH. ${ }^{14-16}$ For example, Balestrino et $a l,{ }^{17} \mathrm{John}$ et $a l^{18}$ and Schwarz et $a l^{19}$ reported that the HS admission has increased in the pandemic period compared with the control period. However, reports of Rameez et $a l,{ }^{16}$ Zini et $a l^{20}$ and Sacco et al showed that the HS admission was reduced in the pandemic period. It makes the impact remain controversial. Moreover, most of these reports are limited to regional or country-specific analysis, and thus, there is no systematic review and meta-analysis on the impact of the COVID-19 pandemic on the HS admission. To further examine whether this pandemic influenced the HS admission, we reviewed recent studies that compared rates of HS admissions

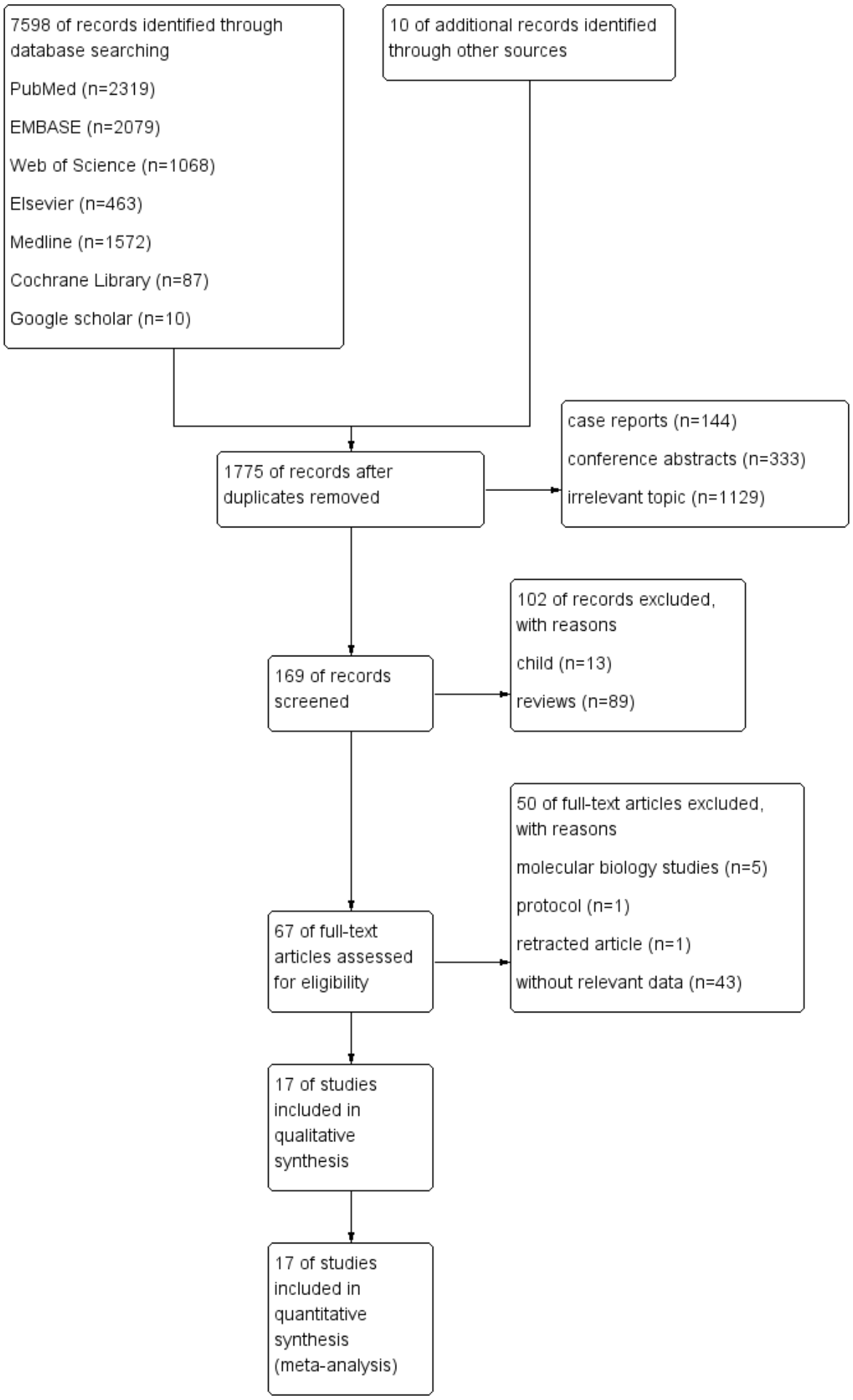

Figure 1 Flow chart of study selection process. 


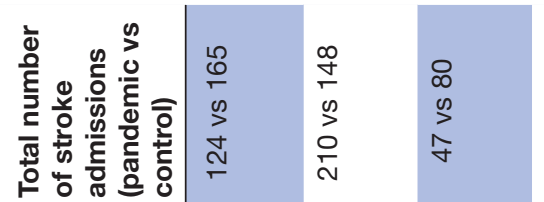

¿

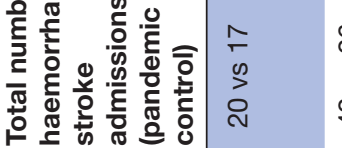

$\overleftarrow{0}$

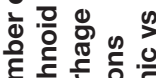

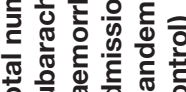

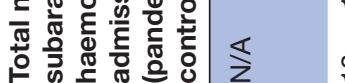

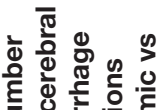

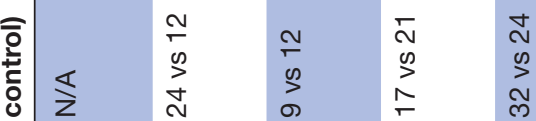

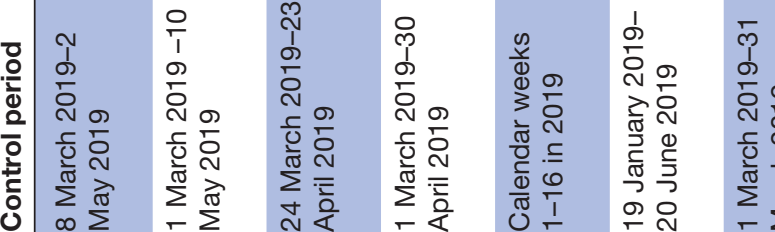

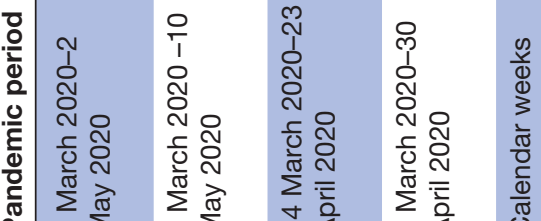

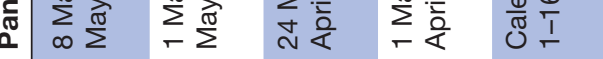

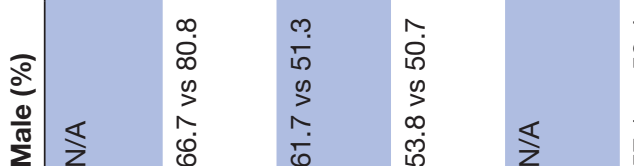

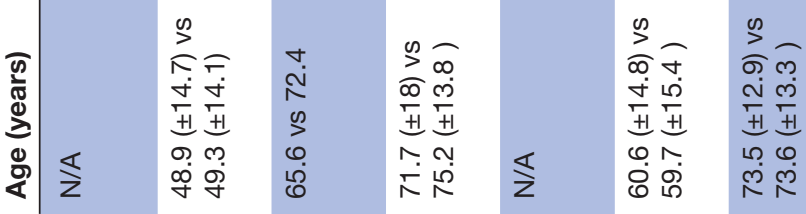

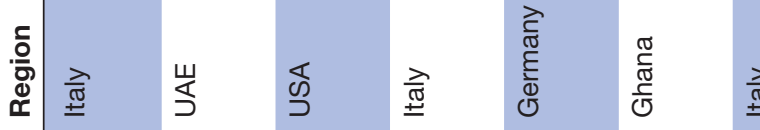

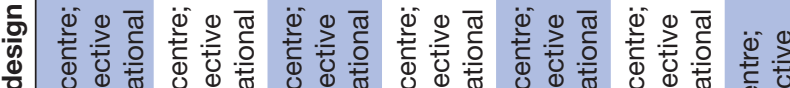

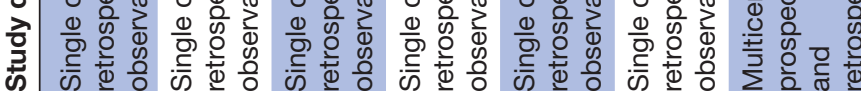

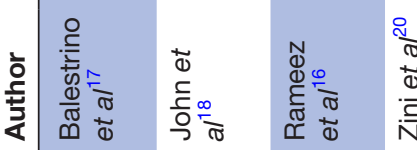

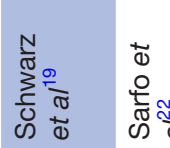

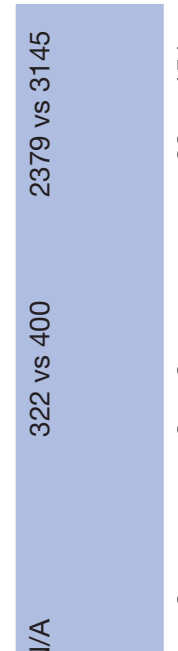

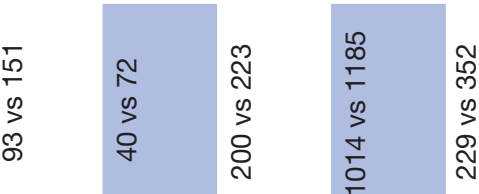

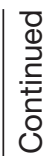

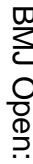

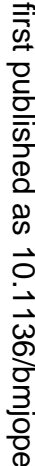

กิ

항

$\vec{A}$

$\overbrace{\mathbb{D}}$

$\frac{0}{3}$

芩



吾

$\frac{\mathrm{o}}{3}$

$\stackrel{\infty}{2}$

งิ $\infty$ ำ

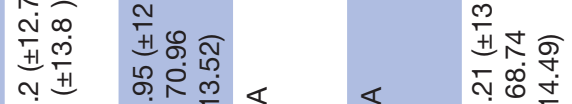

बुछ

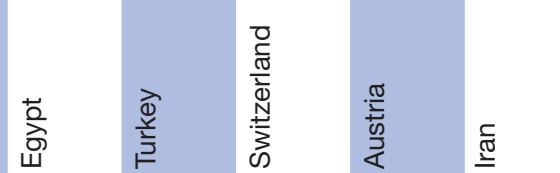

@一

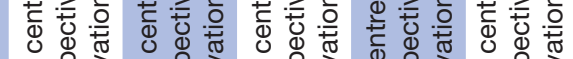

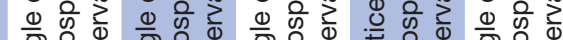

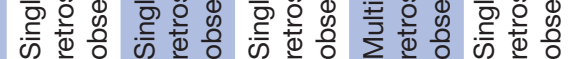

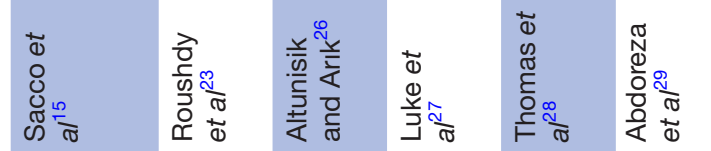




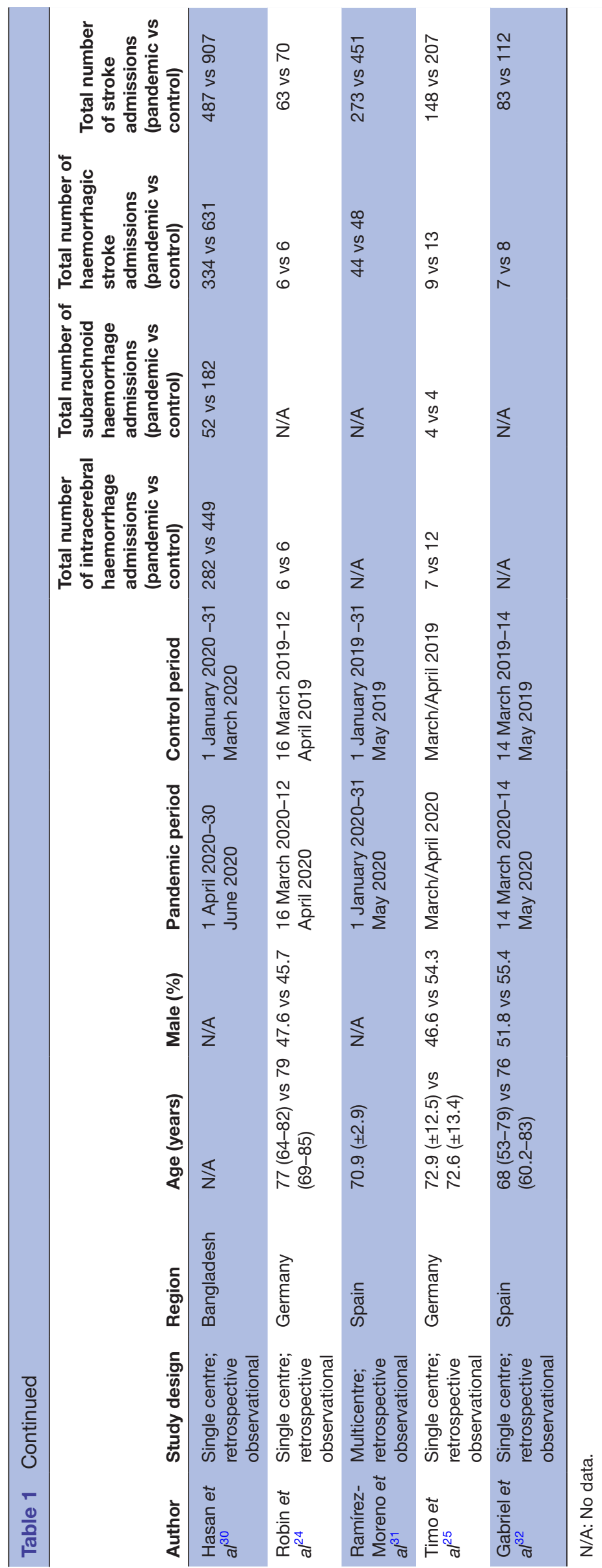

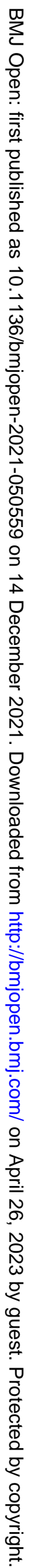


between corresponding periods of pandemic and pre-pandemic.

\section{MATERIALS AND METHODS}

\section{Research strategy and selection criteria}

Our systematic review was conducted in accordance with the Preferred Reporting Items for Systematic Reviews and Meta-Analyses (PRISMA) guidelines. Two authors (YY and $\mathrm{YN}$ ) independently identified studies published until 22 August 2021 through systematically searching EMBASE, PubMed, Web of Science, Elsevier, Medline, Cochrane Library and Google Scholar. The following search key terms were used: stroke, subarachnoid hemorrhage, hemorrhagic stroke, cerebral hemorrhage, COVID-19, SARS-CoV-2, pandemic. We used Boolean operators 'AND' or 'OR' to combine the literature searches (online supplemental appendix 1). No language restrictions were applied. Every eligible publication was selected based on the articles' title and abstract by two authors (YY and YN). If there was any disagreement during study screening for relevance, we discussed it with a senior author (PD). This systematic review and meta-analysis was not registered in the International Prospective Register of Systematic Reviews Database.

The inclusion criteria for this review were original articles, retrospective observational studies, prospective and retrospective studies, and research letters. The data of interest were the ICH, SAH, HS and stroke admissions during the COVID-19 pandemic versus the comparator period. Only studies involving adults were eligible for inclusion. The exclusion criteria included protocols, retracted articles, conference abstracts, preprints, case reports, review articles, biochemical trials, no appropriate outcomes or trials without proper treatment groups and control groups.

\section{Data extraction and quality assessment}

The following data were extracted from each article by two independent researchers (YY and $\mathrm{YN}$ ): author name, publication year, study type and design, source and region of study, patient demographics (age, gender), number of ICH admissions, number of SAH admissions, number of HS admissions and number of stroke admissions. Any conflicts between the researchers were resolved by discussion or decision of a third senior researcher. If there were incomplete data, we attempted to contact the corresponding authors for complete data. We also calculated the necessary information which was not reported in the articles.

The Newcastle-Ottawa Scale was used to evaluate the risk of bias of the included retrospective observational studies. The score consisted of eight items, including adequate case definition, representativeness of cases, selection of controls, definition of controls, comparability, ascertainment of exposure, same method and nonresponse rate. The total quality score ranged between 0 and 9. Studies assessed with $\geq 5$ points were regarded

Table 2 Newcastle-Ottawa quality assessment scale and total score of each study

\begin{tabular}{|c|c|c|c|c|c|c|c|c|c|}
\hline \multirow[b]{2}{*}{ Included studies } & \multicolumn{8}{|c|}{ Newcastle-Ottawa quality assessment scale } & \multirow{2}{*}{$\begin{array}{l}\text { Score } \\
\text { Total of number of stars }\end{array}$} \\
\hline & 1 & 2 & 3 & 4 & 5 & 6 & 7 & 8 & \\
\hline Balestrino et $a 1^{17}$ & B & $A^{*}$ & B & $A^{*}$ & $A^{*}$ & $A^{*}$ & $A^{*}$ & $A^{*}$ & 6 \\
\hline John et al ${ }^{18}$ & $A^{*}$ & $A^{*}$ & B & $A^{*}$ & $A^{*}$ & $A^{*}$ & $A^{*}$ & $A^{*}$ & 7 \\
\hline Rameez et al ${ }^{16}$ & B & $A^{*}$ & B & $A^{*}$ & $A^{*}$ & $A^{*}$ & $A^{*}$ & $A^{*}$ & 6 \\
\hline Zini et $\left.a\right|^{20}$ & $A^{*}$ & $A^{*}$ & B & $A^{*}$ & $A^{*}$ & $A^{*}$ & $A^{*}$ & $A^{*}$ & 7 \\
\hline Schwarz et al ${ }^{19}$ & $B$ & $A^{*}$ & B & $A^{*}$ & $A^{*}$ & $A^{*}$ & $A^{*}$ & $A^{*}$ & 6 \\
\hline Sarfo et a $\left.\right|^{22}$ & B & $A^{*}$ & B & $A^{*}$ & $A^{*}$ & $A^{*}$ & $A^{*}$ & $A^{*}$ & 6 \\
\hline Sacco et $a l^{15}$ & $A^{*}$ & $A^{*}$ & $A^{*}$ & $A^{*}$ & $A^{\star *}$ & $A^{*}$ & $A^{*}$ & $A^{*}$ & 9 \\
\hline Roushdy et $a^{23}$ & B & $B$ & $\mathrm{~B}$ & $A^{*}$ & $A^{*}$ & $A^{*}$ & $A^{*}$ & $A^{*}$ & 5 \\
\hline Altunisik and Arık ${ }^{26}$ & $A^{*}$ & $A^{*}$ & B & $A^{*}$ & $A^{*}$ & $A^{*}$ & $A^{*}$ & $A^{*}$ & 7 \\
\hline Luke et $a l^{27}$ & $A^{*}$ & $A^{*}$ & B & $A^{*}$ & $A^{*}$ & $A^{*}$ & $A^{*}$ & $A^{*}$ & 7 \\
\hline Thomas et $a l^{28}$ & $A^{*}$ & $A^{*}$ & $A^{*}$ & $A^{*}$ & $A^{*}$ & $A^{*}$ & $A^{*}$ & $A^{*}$ & 8 \\
\hline Abdoreza et al ${ }^{29}$ & $\mathrm{~B}$ & $A^{*}$ & $B$ & $A^{*}$ & $A^{*}$ & $A^{*}$ & $A^{*}$ & $A^{*}$ & 6 \\
\hline Hasan et a ${ }^{30}$ & $A^{*}$ & $B$ & $A^{*}$ & $A^{*}$ & B & $A^{*}$ & $A^{*}$ & $A^{*}$ & 6 \\
\hline Robin et $a l^{24}$ & $A^{*}$ & $A^{*}$ & $A^{*}$ & $A^{*}$ & $A^{*}$ & $A^{*}$ & $A^{*}$ & $A^{*}$ & 8 \\
\hline Ramírez-Moreno et a $\left.\right|^{31}$ & $A^{*}$ & $A^{*}$ & $B$ & $A^{*}$ & $A^{*}$ & $A^{*}$ & $A^{*}$ & $A^{*}$ & 7 \\
\hline Timo et $a^{25}$ & $A^{*}$ & $A^{*}$ & $A^{*}$ & $A^{*}$ & $A^{*}$ & $A^{*}$ & $A^{*}$ & $A^{*}$ & 8 \\
\hline Gabriel et al ${ }^{32}$ & $A^{*}$ & $A^{*}$ & $A^{*}$ & $A^{*}$ & $A^{\star \star}$ & $A^{*}$ & $A^{*}$ & $A^{*}$ & 9 \\
\hline
\end{tabular}

$A^{*}$, one star; $A^{* *}$, two stars; $B$, no star; 1 , adequate case definition; 2 , representativeness of cases; 3 , selection of controls; 4 , definition of controls; 5 , comparability; 6 , ascertainment of exposure; 7 , same method; 8 , non-response rate. 
as low risk of bias, compared with the studies scoring $<5$ points that were regarded as high risk of bias.

\section{Data synthesis and analysis}

Meta-analysis of proportion was used to determine ICH, $\mathrm{SAH}, \mathrm{HS}$ and stroke admissions during the pandemic compared with that during the historical pre-pandemic control period. The present study was performed by using Review Manager (V.5.3.0) software. Heterogeneity was calculated by using $Q$ test and $\mathrm{I}^{2}$, in which $\mathrm{p}<0.1, \mathrm{I}^{2}>50 \%$ meant significant heterogeneity. A fixed-effects model was used when statistically indicated heterogeneity was not found $\left(\mathrm{p}>0.1, \mathrm{I}^{2}<50 \%\right)$.
Sensitivity analysis was used to assess the impact of individual articles. If there were a limited number of studies $(<10)$, an assessment for publication bias was not performed. Conversely, publication bias was analysed and represented by a funnel plot that allowed evaluation of publication bias by presenting the study's log OR as a function of its SE.

\section{Patient and public involvement}

This is a meta-analysis based on study-level data and no individual-level data were involved in the study or in defining the research question or outcome measures.

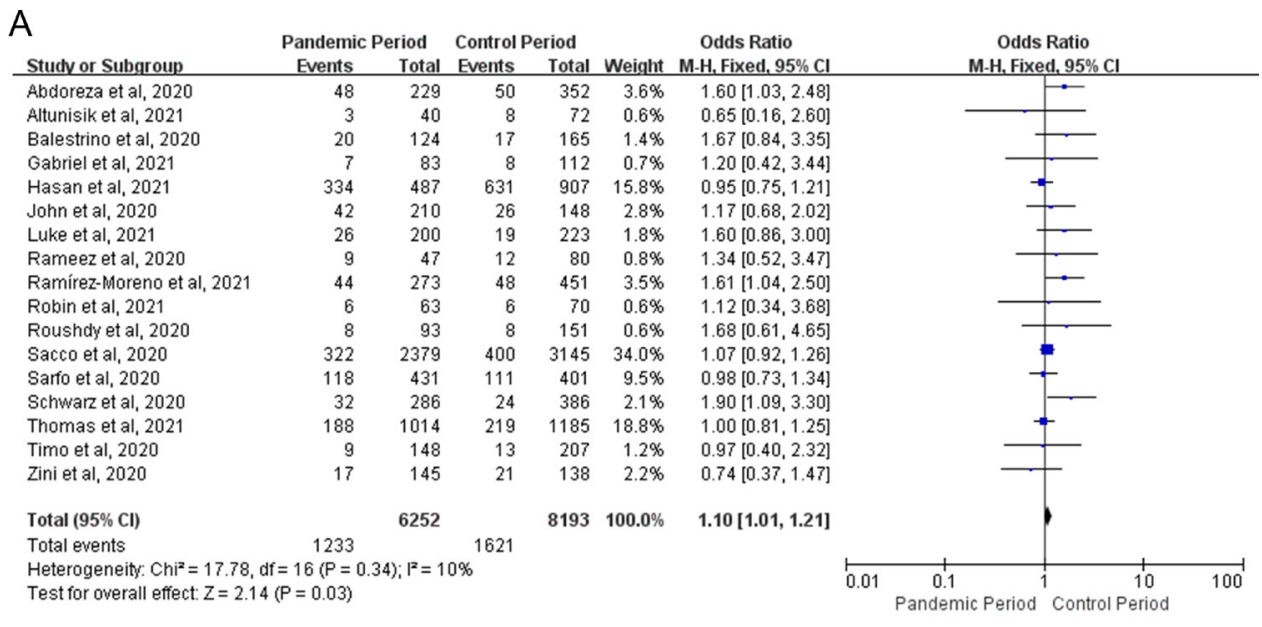

B

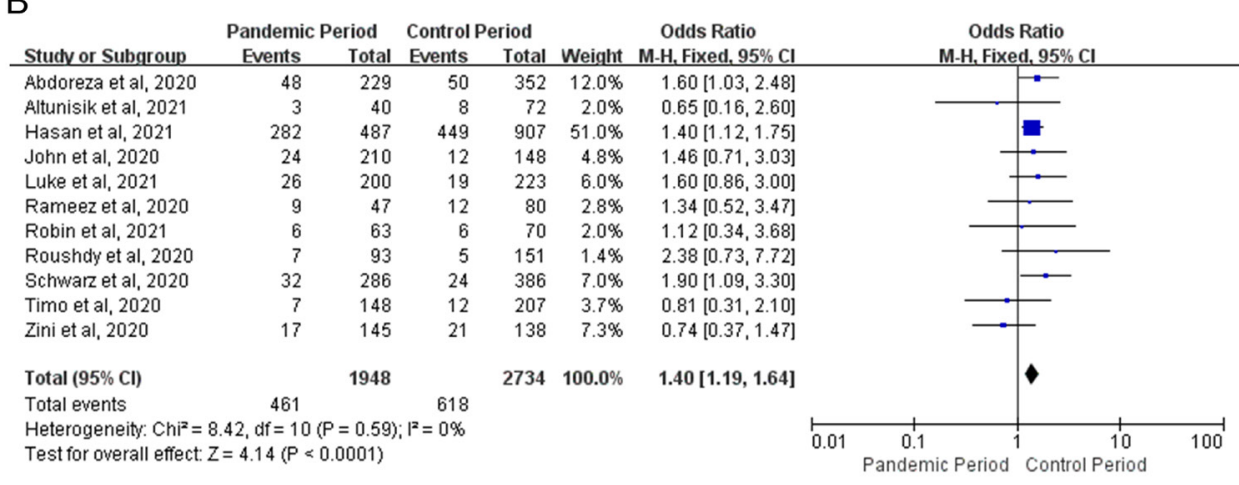

C

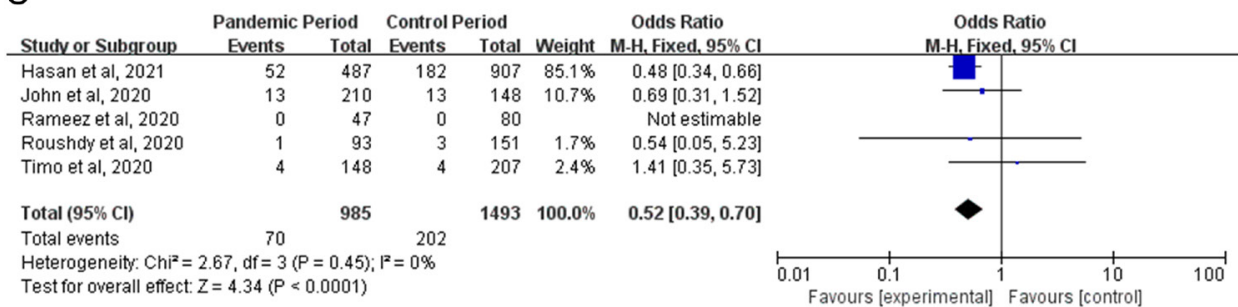

Figure 2 (A) Forest plot showing the HS admission during the pandemic compared with the control period. (B) Forest plot showing the $\mathrm{ICH}$ admission during the pandemic compared with the control period. (C) Forest plot showing the SAH admission during the pandemic compared with the control period. HS, haemorrhagic stroke; $\mathrm{ICH}$, intracerebral haemorrhage; $\mathrm{SAH}$, subarachnoid haemorrhage. 
A

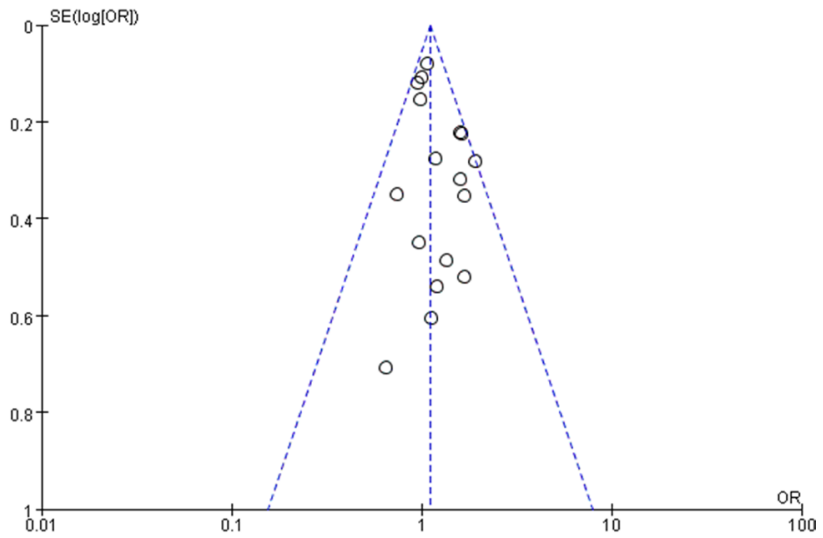

B

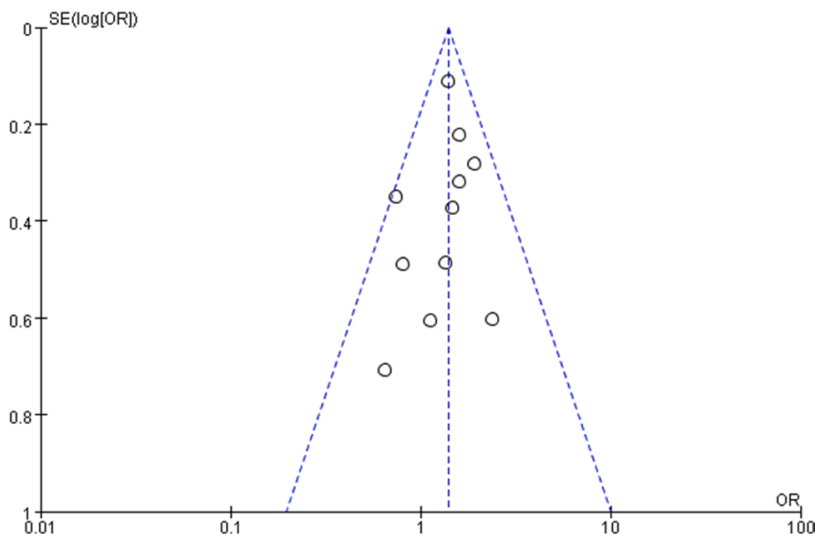

Figure 3 Funnel plot with the pooled estimate of the fixed-effects model. (A) The funnel plot of HS group. (B) The funnel plot of ICH group. HS, haemorrhagic stroke; $\mathrm{ICH}$, intracerebral haemorrhage

\section{RESULTS}

\section{Study selection}

By using the key phrases mentioned above, the literature search yielded 7608 articles from the following databases: 2319 from PubMed, 2079 from EMBASE, 1068 from Web of Science, 463 from Elsevier, 1572 from Medline, 87 from Cochrane Library, 10 from Google Scholar and 10 from other sources. A total of 1775 articles were retained after removal of duplicates. A total of 1708 records were excluded after screening the titles and abstracts, leaving 67 eligible studies. After the full texts were assessed for eligibility, we excluded 50 articles for the following reasons: (1) molecular biology studies $(\mathrm{n}=5),(2)$ protocol $(\mathrm{n}=1)$, (3) retracted article $(\mathrm{n}=1)$, (4) without relevant data $(n=43)$. Finally, 17 studies were eligible and included in our systematic review. ${ }^{15-23}$ A PRISMA diagram detailing the study selection process is shown in figure 1 .

\section{Characteristics of included studies}

The main characteristics of included studies, including author, the design of study, country or region, age, male to female ratio, pandemic period, control period and each disease admission are summarised in table 1.

A total sample of 14445 subjects from 17 studies was included in the systematic review. The studies were conducted in many countries worldwide including Italy, ${ }^{15}{ }^{17} 20$ United Arab Emirates, ${ }^{18}$ the USA, ${ }^{16}$ Germany, ${ }^{192425}$ Ghana, ${ }^{22}$ Turkey ${ }^{26}$ Switzerland,${ }^{27}$ Austria, ${ }^{28}$ Iran, ${ }^{29}$ Bangladesh ${ }^{30}$ Spain ${ }^{31} 32$ and Egypt. ${ }^{23}$ These studies included retrospective-observational studies and prospective and retrospective studies. All studies were reported on the number of ICH, SAH, HS and stroke admissions during the COVID-19 pandemic compared with the control period.

\section{Risk of bias within studies}

The Newcastle-Ottawa score results for each study were shown in table 2. All of these studies were assessed as having a low risk of bias.

\section{Synthesis of results}

\section{Haemorrhagic stroke}

The HS admission was reported in 17 articles. ${ }^{15-2022-28} 30-32$ In HS, the pandemic group has 1233 of 6252 cases and the control group has 1621 of 8193 cases. The proportion of HS admissions is higher at stroke admissions in the pandemic period than the proportion of HS admissions in the control period. The difference is significant (OR $1.10,95 \%$ CI 1.01 to $1.21, \mathrm{I}^{2}=10 \%, \mathrm{p}=0.03$ ) (figure $2 \mathrm{~A}$ ). Figure 3A shows a funnel plot for the visual inspection of publication bias. The plot shows there is no significant publication bias.

\section{Subgroup analysis}

To explore the reason for the increased proportion of HS admissions in the pandemic, we conducted a subgroup analysis based on disease categories. In ICH, the admission was reported in 11 articles. $^{16}{ }^{18-20} 23-272930$ It was present in 461 of 1948 cases in the pandemic group and 618 of 2734 cases in the control group, with statistically significant differences between two groups (OR 1.40, $95 \%$ CI 1.19 to $1.64, \mathrm{I}^{2}=0 \%, \mathrm{p}<0.0001$ ) (figure $2 \mathrm{~B}$ ). The funnel plot shows there is no significant publication bias (figure 3B). In SAH, only five articles showed the SAH admission. ${ }^{1618}{ }^{23}$ Seventy of 985 cases in the pandemic group and 202 of 1493 cases in the control group suffered from SAH. The difference is significant (OR $0.52,95 \% \mathrm{CI}$ 0.39 to $0.70, \mathrm{I}^{2}=0 \%, \mathrm{p}<0.0001$ ) (figure $2 \mathrm{C}$ ).

\section{Sensitivity analysis}

Sensitivity analysis shows that the study of Hasan $e t a e^{30}$ has a significant impact on the outcomes of SAH. As for the outcomes of HS and ICH, there is no individual study that has a significant impact on the outcomes.

\section{DISCUSSION}

In this review, the result shows that the number of stroke admissions is reduced in the COVID-19 pandemic. Although the HS admissions are less during the pandemic 
period than during the pre-pandemic period, the proportion of HS hospitalisations in stroke hospitalisations is significantly increased. Our results further indicate that the number of ICH admissions reduces from 618 in the pandemic group to 461 in the control group, with a corresponding rate raised. As for $\mathrm{SAH}$, the number of SAH admissions and the proportion of $\mathrm{SAH}$ admissions are less during the pandemic period than during the control period, but sensitivity analysis indicates that exclusion of an article (Hasan et al) influences the pooled estimates.

The WSO survey indicated that the COVID-19 pandemic had a momentous impact on stroke care with delayed presentation and reduced hospital admissions. Our results further support the decreased trend in stroke admissions during the pandemic period by analysing 14445 cases from 17 studies. However, our results on overall strokes might not be comprehensive, because we only considered studies that reported data on HS separately. Although different search strategies are used to weaken the study selection bias, we think that the bias is an objective existence. At all events, the phenomenon of reduced stroke admissions is certain. We find three possible reasons to explain this phenomenon. First, patients who had a stroke and mild symptoms preferred to stay at home and rejected the emergency department for treatment in the pandemic period. Second, increased social isolation decreased the discovery rate of patients who had a stroke, because their friends or family members could not recognise who was suffering from a stroke. Third, under city lockdown, limited transportation made some patients hardly acquire ambulances and drivers, which delayed the treatment for stroke. So we appeal that local government should carry out focused education and intervention for high-risk groups, and provide a green channel for the treatment of strokes. On the other hand, people should strengthen their connection with relatives and friends by phone or online video.

Additionally, we document a numerically higher proportion of HS admissions in stroke admissions and notice that ICH has a significant increase in occurrence during the epidemic. In a previous review and meta-analysis of the risk factors for spontaneous ICH, we identified hypertension and alcohol intake as important risk factors. ${ }^{33}$ We further found some studies reported that the pandemic led to an increase in alcohol consumption and alcohol abuse which may be attributed to the stress and isolation experienced with the current pandemic. ${ }^{34-44}$ Therefore, we think that the significant increase of ICH is related to alcohol abuse and stress during the pandemic. But the authenticity needs further validation by special studies. In addition, the data variability is small, because patients with ICH kept seeking hospital care in emergency medical services in the pandemic as they had done in pre-pandemic (eg, the emergency was way heavily avoided that some patients with mild symptoms choose to keep away from hospitals). In summary, in this particular period, the quarantine and social isolation just like some degree of grouping exclude other potentially confounding risk factors. It makes us have gained a deeper appreciation of obvious risk factors for ICH. In view of the above-mentioned facts, we wish to make the following proposals: (1) people should pay more attention to modifiable risk factors such as alcohol intake and hypertension to reduce the risk of ICH in the COVID-19 pandemic period; (2) various health organisations and clinicians should develop recommendations for people on how to have a healthy lifestyle to cope with physical distancing and social isolation; (3) governments should explore effective prevention and intervention measures to prevent crises. As for SAH, we think it is hard to acquire any important conclusions due to too little data and a huge impact of a single article. It needs more authoritative studies to explore the impact of COVID-19 pandemic on SAH.

\section{Limitations}

Limitations to this study are the lack of information about stroke severity and prognoses, which might have to some extent underestimated the impact of the pandemic on stroke. Moreover, the total number of admissions in the pandemic is not reported, so the prevalence of stroke is inconclusive. Although our meta-analysis indicates higher morbidity of $\mathrm{HS}$ and ICH, the reliability needs to be verified by further researches because of the small sample size. Despite this, this study still has notable clinical and public health implications. For example, our data may encourage people to conduct further research to prove the potential pathogenesis of ICH. On the other hand, our results could attract more attention to the influence of COVID-19, thus people can perfect isolation approaches and prevention measures.

\section{Conclusions}

The study identifies moderate reductions in stroke admissions during the COVID-19 pandemic. Studies have shown that alcohol abuse and stress are important causes of increased ICH hospitalisations during the pandemic. All governments, healthcare institutions, clinicians and academics should aim at preventing potential crisis in the COVID-19 pandemic, exploring more effective policies for prevention and intervention.

Contributors YY conceived and designed the study and drafted the manuscript. YY and YN acquired the data and performed data extraction. YY interpreted the data and performed extensive research on the topic. YY performed the statistical analysis and made all tables and figures. FS, JZ and SH checked the data. PD funded the project. PD and XW supervised the project. YY is the guarantor. All authors contributed to the accomplishment of the manuscript.

Funding The study was supported by the Science and Technology Support Project of Committee of Science and Technology of Chongming District (No. CKY2019-13 to PD).

Competing interests None declared.

Patient consent for publication Not required.

Ethics approval Neither ethics approval nor participant consent was required as this study was based solely on the summary results of previously published articles. Individual patient data were not obtained or accessed.

Provenance and peer review Not commissioned; externally peer reviewed.

Data availability statement Data are available upon reasonable request. The data are available from the corresponding author (cematianya@foxmail.com) upon request. 
Supplemental material This content has been supplied by the author(s). It has not been vetted by BMJ Publishing Group Limited (BMJ) and may not have been peer-reviewed. Any opinions or recommendations discussed are solely those of the author(s) and are not endorsed by BMJ. BMJ disclaims all liability and responsibility arising from any reliance placed on the content. Where the content includes any translated material, BMJ does not warrant the accuracy and reliability of the translations (including but not limited to local regulations, clinical guidelines, terminology, drug names and drug dosages), and is not responsible for any error and/or omissions arising from translation and adaptation or otherwise.

Open access This is an open access article distributed in accordance with the Creative Commons Attribution Non Commercial (CC BY-NC 4.0) license, which permits others to distribute, remix, adapt, build upon this work non-commercially, and license their derivative works on different terms, provided the original work is properly cited, appropriate credit is given, any changes made indicated, and the use is non-commercial. See: http://creativecommons.org/licenses/by-nc/4.0/.

\section{ORCID iD}

Yijie You http://orcid.org/0000-0003-4062-4347

\section{REFERENCES}

1 Huang C, Wang Y, Li X, et al. Clinical features of patients infected with 2019 novel coronavirus in Wuhan, China. Lancet 2020;395:497-506.

2 Sohrabi C, Alsafi Z, O'Neill N, et al. World Health Organization declares global emergency: a review of the 2019 novel coronavirus (COVID-19). Int J Surg 2020;76:71-6.

3 Lipsitch M, Swerdlow DL, Finelli L. Defining the epidemiology of covid-19 - studies needed. N Engl J Med 2020;382:1194-6.

4 World Health Organization. Coronavirus disease (covid-19): weekly epidemiological, update 1, 2020.

5 GBD, Stroke, Collaborators. Global, regional, and national burden of stroke, 1990-2016: a systematic analysis for the global burden of disease study 2016. Lancet 2019.

6 GBD 2016 Lifetime Risk of Stroke Collaborators, Feigin VL, Nguyen $\mathrm{G}$, et al. Global, regional, and country-specific lifetime risks of stroke, 1990 and 2016. N Engl J Med 2018;379:2429-37.

7 O'Donnell MJ, Chin SL, Rangarajan S, et al. Global and regional effects of potentially modifiable risk factors associated with acute stroke in 32 countries (INTERSTROKE): a case-control study. Lancet 2016;388:761-75.

8 Krishnamurthi RV, Ikeda T, Feigin VL. Global, regional and countryspecific burden of ischaemic stroke, intracerebral haemorrhage and subarachnoid haemorrhage: a systematic analysis of the global burden of disease study 2017. Neuroepidemiology 2020;54:171-9.

9 Pandian JD, Gall SL, Kate MP, et al. Prevention of stroke: a global perspective. Lancet 2018;392:1269-78.

10 Kimura K. [diagnosis and treatment in acute stroke]. Rinsho Shinkeigaku 2010;50:783-6.

11 Solomon MD, McNulty EJ, Rana JS, et al. The covid-19 pandemic and the incidence of acute myocardial infarction. $N$ Engl J Med 2020;383:691-3.

12 July J, Pranata R. Impact of the coronavirus disease pandemic on the number of strokes and mechanical thrombectomies: a systematic review and meta-analysis. J Stroke Cerebrovasc Dis 2020;29:105185.

13 Markus HS, Brainin M. COVID-19 and stroke-A global world stroke organization perspective. Int J Stroke 2020;15:361-4.

14 Wang X, Dong Y, Qi X, et al. Cholesterol levels and risk of hemorrhagic stroke: a systematic review and meta-analysis. Stroke 2013;44:1833-9.

15 Sacco S, Ricci S, Ornello R, et al. Reduced admissions for cerebrovascular events during covid-19 outbreak in Italy. Stroke 2020;51:3746-50.

16 Rameez F, McCarthy P, Cheng Y, et al. Impact of a stay-at-home order on stroke admission, subtype, and metrics during the covid-19 pandemic. Cerebrovasc Dis Extra 2020;10:159-65.

17 Balestrino M, Coccia A, Boffa AS. Request of hospital care dropped for TIA but remained stable for stroke during covid-19 pandemic at a large Italian university hospital. Intern Emerg Med 2020:1-5.

18 John S, Hussain SI, Piechowski-Jozwiak B, et al. Clinical characteristics and admission patterns of stroke patients during the COVID 19 pandemic: a single center retrospective, observational study from the abu dhabi, United Arab Emirates. Clin Neurol Neurosurg 2020;199:106227.

19 Schwarz V, Mahfoud F, Lauder L, et al. Decline of emergency admissions for cardiovascular and cerebrovascular events after the outbreak of COVID-19. Clin Res Cardiol 2020;109:1500-6.
20 Zini A, Romoli M, Gentile M, et al. The stroke mothership model survived during COVID-19 era: an observational single-center study in Emilia-Romagna, Italy. Neurol Sci 2020;41:3395-9.

21 Luostarinen T, Virta J, Satopää J, et al. Intensive care of traumatic brain injury and aneurysmal subarachnoid hemorrhage in Helsinki during the Covid-19 pandemic. Acta Neurochir 2020;162:2715-24.

22 Sarfo FS, Mensah NO, Opoku FA, et al. COVID-19 and stroke: experience in a Ghanaian healthcare system. J Neurol Sci 2020;416:117044.

23 Roushdy TM, Nahas NME, Aref HM, et al. Stroke in the time of coronavirus disease 2019: experience of two university stroke centers in Egypt. J Stroke 2020;22:275-7.

24 Jansen R, Lee J-I, Turowski B, et al. Consequences of COVID-19 pandemic lockdown on emergency and stroke care in a German tertiary stroke center. Neurol Res Pract 2021;3.

25 Uphaus T, Gröschel S, Hayani E, et al. Stroke care within the COVID-19 pandemic-increasing awareness of transient and mild stroke symptoms needed. Front Neurol;11.

26 Altunıșık E, Arık A. Decreased stroke applications during pandemic: collateral effects of covid-19. Turkish J Neurology/Turk Noroloji Dergisi 2021;27.

27 Carson L, Kui C, Smith G, et al. The effect of the 2019 novel coronavirus pandemic on stroke and TIA patient admissions: perspectives and risk factors. J Clin Med 2021;10:1357.

28 Gattringer T, Fandler-Höfler S, Kneihsl M, et al. Hospital admissions of acute cerebrovascular diseases during and after the first wave of the COVID-19 pandemic: a state-wide experience from Austria. J Neurol 2021;268:3584-8.

29 Ghoreishi A, Arsang-Jang S, Sabaa-Ayoun Z, et al. Stroke care trends during covid-19 pandemic in zanjan Province, Iran. from the cascade initiative: statistical analysis plan and preliminary results. J Stroke Cerebrovasc Dis 2020;29:105321.

30 Hasan ATMH, Das SC, Islam MS, et al. Impact of COVID-19 on hospital admission of acute stroke patients in Bangladesh. PLoS One;16:e0240385.

31 Ramírez-Moreno JA-O, Portilla-Cuenca JC, HariramaniRamchandani R, et al. Slump in hospital admissions for stroke, a fact of an uncertain nature that requires explanation. lid.

32 Velilla-Alonso G, García-Pastor A, Rodríguez-López Ángela, et al. Acute stroke care during the covid-19 pandemic: reduction in the number of admissions of elderly patients and increase in prehospital delays. Cerebrovasc Dis 2021;50:310-6.

33 Ariesen MJ, Claus SP, Rinkel GJE, et al. Risk factors for intracerebral hemorrhage in the general population: a systematic review. Stroke 2003;34:2060-5.

34 Ćosić K, Popović S, Šarlija M, et al. Impact of human disasters and covid-19 pandemic on mental health: potential of digital psychiatry. Psychiatr Danub 2020;32:25-31.

35 Sun Y, Li Y, Bao Y, et al. Brief report: increased addictive Internet and substance use behavior during the covid-19 pandemic in China. Am J Addict 2020;29:268-70.

36 Colbert S, Wilkinson C, Thornton L, et al. COVID-19 and alcohol in Australia: industry changes and public health impacts. Drug Alcohol Rev 2020;39:435-40.

$37 \mathrm{Kmiec}$ J. President's message: the impact of the COVID-19 public health emergency on the practice of addiction medicine. J Addict Dis 2020;38:235-6.

38 Andrade C. COVID-19 and lockdown: delayed effects on health. Indian J Psychiatry 2020;62:247-9.

39 Rehm J, Kilian C, Ferreira-Borges C, et al. Alcohol use in times of the COVID 19: implications for monitoring and policy. Drug Alcohol Rev 2020;39:301-4.

40 Carrico AW, Horvath KJ, Grov C, et al. Double jeopardy: methamphetamine use and HIV as risk factors for covid-19. AIDS Behav 2020;24:3020-3.

41 Clay JM, Parker MO. Alcohol use and misuse during the COVID-19 pandemic: a potential public health crisis? Lancet Public Health. 2020;5:e259.

42 Shigemura J, Ursano RJ, Morganstein JC, et al. Public responses to the novel 2019 coronavirus (2019-nCoV) in Japan: mental health consequences and target populations. Psychiatry Clin Neurosci 2020;74:281-2.

43 Wang Y, Di Y, Ye J, et al. Study on the public psychological states and its related factors during the outbreak of coronavirus disease 2019 (COVID-19) in some regions of China. Psychol Health Med 2021;26:13-22

44 Ramalho R. Alcohol consumption and alcohol-related problems during the COVID-19 pandemic: a narrative review. Australas Psychiatry 2020;28:524-6. 